\title{
PENGARUH BUDAYA PERUSAHAAN, KOMITMEN EFEKTIF DAN KOMITMEN NORMATIF TERHADAP KINERJA KARYAWAN (STUDI PADA KARYAWAN PT. BANK BUKOPIN, TBK KANTOR PUSAT)
}

\author{
Robbi $^{1}$, Meita Pragiwani ${ }^{2}$ \\ Program Pascasarjana Manajemen \\ Sekolah Tinggi Ilmu Ekonomi Indonesia \\ obbipage@gmail.com¹, ola_168@yahoo.com²
}

\begin{abstract}
ABSTRAK
Dalam data Key Performance Indicator (KPI) yang dimiliki oleh Bank Bukopin data kinerja Bank Bukopin Periode 20142016, terdapat informasi pencapaian kinerja dalam rentang waktu 2014 - 2016 yang tidak maksimal. Dari hasil survei yang telah dilakukan perusahaan tiga tahun Data Responden Employee Engagement Survey (2014-2016), masih terdapat Divisi yang pengisian surveinya dibawah 80\%. Sehingga berpengaruh kepada penilaian Engagement Karyawan. Penelitian ini tentang pengaruh budaya perusahaan, komitmen efektif dan komitmen normatif terhadap kinerja karyawan PT. Bank Bukopin. Dimana budaya perusahaan sebagai variabel $\mathrm{X}_{1}$, Komitmen Afektif variabel $\mathrm{X}_{2}$, Komitmen Normatif variabel $\mathrm{X}_{3}$ dan kinerja karyawan merupakan variabel $\mathrm{Y}$. Metode yang digunakan dalam penelitian ini penelitian kuantitatif dengan menggunakan metode asosiatif yang dilakukan dengan menggunakan pendekatan survei. Hasil penelitian menunjukkan pengaruh antara budaya perusahaan dengan kinerja karyawan dengan tingkat signifikansi 0,116 $>0,05$, berarti tidak ada pengaruh yang signifikan antara promosi dengan minat kuliah. Pengaruh antara komitmen afektif terhadap kinerja karyawan telah terbukti. Hal ini terbukti melalui penelitian dengan hasil signifikansi 0,000 yang lebih kecil dari 0,05 yang menunjukan bahwa komitmen afektif memiliki hubungan positif dan signifikan terhadap kinerja karyawan. Pengaruh antara budaya perusahaan, komitmen afektif dan komitmen normatif terhadap kinerja karyawan dengan uji F maka diperoleh nilai F hitung > F tabel, 77,353 tingkat signifikansi 0,00<0,05. berarti secara bersama-sama budaya perusahaan, komitmen afektif, komitmen normatif berpengaruh positif dan signifikan terhadap kinerja karyawan.
\end{abstract}

Kata Kunci: Budaya Perusahaan, Komitmen Efektif, Komitmen Normatif, Kinerja

\begin{abstract}
In the Key Performance Indicator (KPI) data held by Bank Bukopin, Bank Bukopin's performance data for the $2014-2016$ period, there was information on performance achievements in the 2014-2016 period which were not optimal. From the results of a survey conducted by a three-year company Data on Respondents of the Employee Engagement Survey (20142016), there are still Divisions that fill the survey below 80\%. So that affects the assessment of Employee Engagement. This research is about the influence of corporate culture, effective commitment and normative commitment to the performance of employees of PT. Bank Bukopin. Where corporate culture as variable X1, Affective Commitment variable X2, Normative Commitment variable X3 and employee performance is variable Y. The method used in this study is quantitative research using associative methods carried out using a survey approach. The results showed the influence between corporate culture and employee performance with a significance level of 0.116>0.05, meaning there was no significant influence between promotions and college interests. The effect of affective commitment on employee performance has been proven. This is evident through research with a significance value of 0,000 which is smaller than 0.05 which indicates that affective commitment has a positive and significant relationship to employee performance. Influence between corporate culture, affective commitment and normative commitment to employee performance with $F$ test, obtained F count $>$ F table, 77.353 significance level $0.00<0.05$. means that together corporate culture, affective commitment, normative commitment has a positive and significant effect on employee performance.
\end{abstract}

Keywords: Corporate Culture, Effective Commitment, Normative Commitment, Performance 


\section{Pengaruh Budaya Perusahaan, Komitmen Efektif Dan Komitmen Normatif Terhadap Kinerja Karyawan (Studi Pada Karyawan Pt. Bank Bukopin, Tbk Kantor Pusat) \\ (Robbi, Meita Pragiwani)}

\section{PENDAHULUAN}

Bank sebagai salah satu jasa keuangan juga harus ikut andil dalam mengikuti perkembangan ekonomi yang terus melesat. Salah satu elemen yang diperlukan dengan kesiapan Sumber Daya Manusia (SDM) yang memiliki etos kerja yang baik sehingga menghasilkan kinerja yang baik pula. Bank Bukopin sebagai salah satu bank swasta terbesar di Indonesia bertekad untuk memanfaatkan sumber daya yang ada dengan meningkatkan kinerja dari tahun ketahun. Peningkatan kinerja yang dilakuakn dengan mengidentifikasi SDM serta mengambil langkahlangkah strategis untuk terus meningkatkan kinerja dan pertumbuhan usaha. Bank Bukopin telah menetapkan target untuk tumbuh berkelanjutan dan berkualitas, melalui peningkatan produktivitas, kualitas dan efisiensi. Oleh karena itu pada tahun 2017 Perseroan telah menetapkan 5 (lima) pilar pertumbuhan berkelanjutan. Pilar pertama adalah fokus pada core
Respect Others, Integrity, Dedicated to Customer, dan excellence) yang menjadi panduan serta pedoman bagi Perseroan baik untuk level manajemen dan karyawan dalam bekerja dan berperilaku.

Komitmen juga merupakan hal yang yang penting karena juga mempengaruhi kinerja karyawan.. Apabila seorang pegawai tidak memiliki komitmen maka apa yang telah ditetapkan oleh perusahaan akan sulit dicapai. Dengan adanya komitmen yang baik dimiliki oleh karyawan tentunya akan menunjang kinerja yang baik pula. Dalam data Key Performance Indicator (KPI) yang dimiliki oleh Bank Bukopin yang dituangkan pada tabel 1.1 Data kinerja Bank Bukopin Periode 2014-2016, terdapat informasi pencapaian kinerja dalam rentang waktu 2014 - 2016 yang tidak maksimal. Sehingga penilaian kinerja Bank Bukopin pada periode tersebut terdapat fluktuasi nilai akhir yang cukup signifikan.

Tabel 1.1 Data Kinerja Bank Bukopin Periode 2014 - 2016

\begin{tabular}{|c|c|c|c|c|c|c|c|c|c|c|c|}
\hline \multirow{2}{*}{ No. } & \multirow{2}{*}{ Strategy Objectives } & \multirow{2}{*}{ KPI } & \multicolumn{3}{|c|}{2014} & \multicolumn{3}{|c|}{2015} & \multicolumn{3}{|c|}{2016} \\
\hline & & & Target & Realisasi & $(\%)$ & Target & Realisasi & $(\%)$ & Target & Realisasi & $(\%)$ \\
\hline 1 & $\begin{array}{l}\text { Peningkatan Aset dan } \\
\text { Kualitasnya }\end{array}$ & NPL (RP.Juta) & 889 & 1378 & $65.20 \%$ & 1099 & 1471 & $74.67 \%$ & 1180 & 2374 & $49.75 \%$ \\
\hline 2 & $\begin{array}{l}\text { Meningkatkan pengembangan } \\
\text { Produk yang berorientasi pada } \\
\text { kebutuhan Costumer }\end{array}$ & 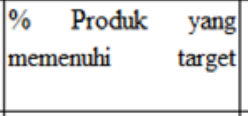 & $80 \%$ & $48 \%$ & $60 \%$ & $80 \%$ & $78.57 \%$ & $98.21 \%$ & $80 \%$ & $57.14 \%$ & $71.43 \%$ \\
\hline 3 & $\begin{array}{l}\text { Mengoptimalkan produktivitas } \\
\text { sales dengan Costumer } \\
\text { manajemen }\end{array}$ & $\begin{array}{|lr|}\% & \text { Karyawan } \\
\text { marketing } & \text { yang } \\
\text { mencapai } & \text { target } \\
\end{array}$ & $75 \%$ & $21.79 \%$ & $29.05 \%$ & $75 \%$ & $30.45 \%$ & $40.60 \%$ & $75 \%$ & $29.75 \%$ & $39.67 \%$ \\
\hline
\end{tabular}

*Sumber data KPI PT. Bank Bukopin, Tbk (2014-2016)

bisnis yaitu secara konsisten menerapkan fokus pada segmen bisnis dan produk unggulan. Pilar kedua adalah orientasi pada customer loyalty dengan orientasi pelayanan adalah kepuasan customer, khususnya dalam hal kecepatan dan kemudahan. Pilar ketiga adalah disiplin proses yang merupakan upaya meningkatkan disiplin proses bisnis, proses pelayanan, maupun tata kelola (good corporate governance) yang optimal. Pilar keempat adalah duplikasi dan inovasi, yang meliputi penerapan pola yang sudah berhasil dilakukan, pembentukan sikap SDM yang adaptif terhadap perubahan dan inovasi baru, peningkatan kompetensi SDM. Dan pilar kelima adalah produk unik dan unggul.

Budaya Perusahaan dan kesadaran akan arti penting implementasi GCG dilakukan dengan proses internalisasi kedalam sistem dan prosedur serta pembentukan budaya sesuai dengan nilai-nilai norma yang berlaku. Dalam menetapkan standar penerapan GCG diimplementasikan dalam visi dan misi Bank Bukopin yang dirumuskan dalam Nilai-nilai Budaya Perusahaan yang disebut dengan PRIDE (Profesional,
Kinerja karyawan Bank Bukopin harus terus ditingkatkan sesuai dengan target yang diberikan oleh stakeholder. Setiap tahun kerja, karyawan juga diwajibkan melakukan pengisian Employee Engagement Survey. Pengisian survei ini berpengaruh juga terhadap KPI masing-masing Divisi pada point Meningkatkan Enagement karyawan. Dari hasil survei yang telah dilakukan perusahaan tiga tahun Data Responden Employee Engagement Survey (20142016), masih terdapat Divisi yang pengisian surveinya dibawah 80\%. Sehingga berpengaruh kepada penilaian Engagement Karyawan. Hal ini menyebabkan penulis ingin melakukan penelitian tentang Pengaruh Budaya Perusahaan, Komitmen Afektif, dan Komitmen Normatif Terhadap Kinerja Karyawan (studi pada Karyawan PT. Bank Bukopin, Tbk Kantor Pusat).

\section{TINJAUAN PUSTAKA}

Budaya organisasi itu didasarkan pada suatu konsep bangunan pada tiga tingkatan, yaitu: Tingkatan Asumsi Dasar (Basic Assumption), kemudian Tingkatan Nilai (Value), dan Tingkatan Artifact yaitu 
sesuatu yang ditinggalkan. System nilai tersebut dibangun oleh 7 karakteristik sebagai sari (essence) dari budaya organisasi, 7 karakteristik adalah:

1. Inovasi dan pengambilan risiko (Innovation and risk taking).

2. Perhatian yang rinci (Attention to detail).

3. Orientasi hasil (Outcome orientation).

4. Orientasi pada manusia (People orientation).

5. Orientasi tim (Team orientation).

6. Keagresifan (Aggressiveness).

7. Stabilitas (Stability).

Komitmen Organisasi mempunyai peran penting, karena akan menunjukan adanya rasa keterikatan yang ditunjuk oleh Karyawan kepada organisasi, menurut Laschinger (dalam M.Aditya 2016: 10) komitemen organisasi membahas kedekatan karyawan terhadap organisasi dimana mereka berada. Komitmen terhadap organisasi artinya lebih dari sekedar keanggotaan formal, karena meliputi sikap menyukai organisasi dan kesediaan untuk mengusahakan tingkat upaya yang tinggi bagi kepentingan organisasi demi pencapaian tujuan. Berdasarkan definisi ini, dalam komitmen organisasi tercakup unsur loyalitas terhadap organisasi, keterlibatan dalam pekerjaan, dan identifikasi terhadap nilai-nilai dan tujuan organisasi.

Menurut Kaswan (2012: 187) dalam Parinding (2017) mengemukakan bahwa "Kinerja karyawan adalah yang mempengaruhi seberapa banyak/besar mereka memberi kontribusi organisasi. Menurut Mohammad Faisal Amir (2015: 83) dalam Parinding (2017) mengemukakan dalam konteks manajemen sumber daya manusia, Kinerja karyawan dapat didefinisikan sebagai perilaku atau kegiatan yang ditampilkan oleh seseorang dalam kaitannya dengan tugas kerja di perusahaan, departemen, atau organisasi, dilaksanakan sesuai dengan potensi yang dimilikinya, dalam rangka menghasilkan sesuatu yang bermakna bagi organisasi, masyarakat luas, atau bagi dirinya sendiri. Ada tiga faktor yang berpengaruh terhadap kinerja, yaitu faktor individu, faktor psikologi dan faktor organisasi.

\section{METODOLOGI PENELITIAN}

Jenis penelitian ini adalah penelitian kuantitatif dengan menggunakan metode asosiatif yang dilakukan dengan menggunakan pendekatan survei. Penelitian ini menggunakan dua jenis variabel yaitu variabel independen (variabel yang mempengaruhi) dan variabel dependen (variabel yang dipengaruhi). variabel independen diberi simbol X. Variabel independen dalam penelitian ini terdiri dari tiga variabel yaitu variabel Budaya Perusahaan, Komitmen Afektif, dan Komitmen
Normatif. Variabel dependen diberi simbol Y. Variabel dependen dalam penelitian ini terdiri dari satu variabel yaitu Kinerja Karyawan. Berdasarkan jumlah variabel yang diteliti, dan hubungan antar variabel yang dikaji, maka penelitian ini masuk pada kategori analisis bivariat (bivariate analysis). Dalam penelitian ini terdapat 3 model hubungan yang dikaji dalam analisis bivariat yaitu pengaruh Budaya Perusahaan (X1) terhadap Kinerja Karyawan (Y), Komitmen Afektif (X2) terhadap Kinerja Karyawan (Y), dan Komitmen Normatif (X3) terhadap Kinerja Karyawan (Y).

Populasi yang digunakan dalam penelitian ini berjumlah 260 orang. Metode sampel tidak acak dalam penelitian ini adalah sampling aksidental. Teknik sampling aksidental yaitu teknik penentuan sampel dengan berdasarkan ketidaksengajaan bertemu di tempat penelitian (Sugiyono, 2016: 83). Sampel dalam penelitian ini yaitu karyawan PT. Bank Bukopin Tbk. Kantor Pusat yang tidak sengaja ditemui di tempat penelitian.

Jumlah populasi dalam penelitian ini adalah 260 karyawan sehingga jumlah sampel minimal dapat dihitung dengan menggunakan rumus sebagai berikut:

$$
n=\frac{N}{\left(1+N e^{2}\right)}=\frac{260}{\left(1+260 x(0,05)^{2}\right)}=\frac{260}{1,65}=157.57 \approx 158
$$

Data dalam penelitian ini dianalisis dengan analisis statistik deskriptif dan analisis regresi linier sederhana. Sebelum data dianalisis, dilakukan uji validitas dan reliabilitas data.

\section{PEMBAHASAN}

Pengaruh promosi, motivasi dan harga terhadap minat kuliah program Pasca Sarjana Sekolah Tinggi Ilmu Ekonomi Indonesia (STEI), akan disajikan dalam statistik deskriptif yang dapat dilihat pada tabel di bawah ini :

Berdasarkan tabel di atas hasil statistik deskriptif terlihat bahwa rata-rata (mean) untuk budaya perusahaan sebesar 33,76 dengan standar deviasi sebesar 2,66 dari 163 sampel penelitian. Sedangkan Komitmen Afektif dengan mean sebesar 21,46 dan standar deviasi sebesar 1,441 dengan 163 sampel penelitian. Selanjutnya Komitmen Normatif sebesar 17,06 dengan standar deviasi sebesar 1,519 dari 163 sampel penelitian dan kinerja karyawan dengan ratarata sebesar 63,48 dan standar deviasi sebesar 4,68. Dari hasil statistik deskriptif yang telah dikemukakan di atas maka akan disajikan pembahasan dari hasil uji regresi yang dapat diuraikan sebagai berikut : 


\section{Pengaruh Budaya Perusahaan, Komitmen Efektif Dan Komitmen Normatif Terhadap Kinerja Karyawan (Studi Pada Karyawan Pt. Bank Bukopin, Tbk Kantor Pusat) \\ (Robbi, Meita Pragiwani)}

\section{Descriptive Statistics}

\begin{tabular}{|l|r|r|r|r|r|}
\hline & N & \multicolumn{1}{|c|}{ Minimum } & Maximum & \multicolumn{1}{c|}{ Mean } & \multicolumn{1}{c|}{ Std. Deviation } \\
\hline Budaya Perusahaan & 163 & 26,00 & 39,00 & 33,7607 & 2,66860 \\
Komitmen Afektif & 163 & 17,00 & 25,00 & 21,4601 & 1,44122 \\
Komitmen Normatif & 163 & 12,00 & 20,00 & 17,0675 & 1,51994 \\
Kinerja Karyawan & 163 & 47,00 & 75,00 & 63,4847 & 4,68562 \\
Valid N (listwise) & 163 & & & & \\
& & & & & \\
\hline
\end{tabular}

1) Pengaruh budaya perusahaan terhadap Kinerja Karyawan PT Bank Bukopin, Tbk

Pengaruh antara budaya perusahaan dengan kinerja karyawan dengan tingkat signifikansi 0,116 $>0,05$, berarti tidak ada pengaruh yang signifikan antara promosi dengan minat kuliah. Hal yang sama menurut penelitian yang dilakukan Aldy Saputraa (2016) bahwa tidak terdapat pengaruh yang signifikan secara parsial antara variabel budaya perusahaan terhadap variabel kinerja karyawan. Peneliti menganalisis bahwa faktor budaya perusahaan tidak berpengaruh terhadap kinerja karyawan PT Bank Bukopin, Tbkk belum ada sosialisasi oleh manajemen kepada seluruh karyawan PT Bank Bukopin, Tbk Kantor Pusat. Adapun karyawan yang mendapatkan informasi mengenai budaya perusahaan yang telah berlaku hanya melalui memorandum elektronik saja, karena seharusnya diberikan pendidikan dan pelatihan serta kunjungan langsung untuk sosialisasi internalisasi nilai-nilai budaya perusahaan.

2) Pengaruh komitmen afektif terhadap kinerja karyawan PT Bank Bukopin, Tbk

Pengaruh antara komitmen afektif terhadap kinerja karyawan telah terbukti. Hal ini terbukti melalui penelitian dengan hasil signifikansi 0,000 yang lebih kecil dari 0,05 yang menunjukan bahwa komitmen afektif memiliki hubungan positif dan signifikan terhadap kinerja karyawan..

Penelitian ini didukung oleh penelitian Nedia (2012) yang menyatakan komitmen organisasi berpengaruh positif dan signifikan terhadap kinerja dan menurut Steer (1983:35) menyatakan komitmen organisasi dapat menyebabkan kinerja karyawan yang tinggi. Sehingga hipotesis dua berbunyi "terdapat pengaruh antara komitmen afektif (X2) terhadap Kinerja
Karyawan (Y)” diterima. Pengaruh antara komitmen afektif terhadap kinerja karyawan PT Bank Bukopin, Tbk telah terbukti. Hal ini terbukti melalui penelitian dengan hasil signifikansi 0,000 yang lebih kecil dari 0,05 yang mana menunjukan bahwa komitmen afektif memiliki hubungan positif dan signifikan terhadap Kinerja Karyawan.

3) Pengaruh komitmen normatif terhadap minat kinerja karyawan PT Bank Bukopin, Tbk

Pengaruh antara komitmen normatif terhadap kinerja karyawan telah terbukti. Hal ini terbukti melalui penelitian dengan hasil signifikansi 0,000 yang lebih kecil dari 0,05 yang menunjukan bahwa komitmen normatif memiliki hubungan positif dan signifikan terrhadap kinerja karyawan. Penelitian ini didukung oleh penelitian sebelumnya yaitu Elfina dan Seniati (2014) yang menyatakan komitmen normatif berpengaruh positif dan signifikan terhadap kinerja karyawan serta terdapat teori yang menyatakan faktor -faktor terbentuknya kinerja karyawan yaitu komitmen organisasi (Organ, 2016:15). Sehingga hipotesis tiga berbunyi “terdapat pengaruh antara komitmen normatif (X3) terhadap kinerja karyawan (Y)” diterima.

4) Pengaruh budaya perusahaan, komitmen afektif dan komitmen normatif terhadap kinerja karyawan PT Bank Bukopin, Tbk

Pengaruh antara budaya perusahaan, komitmen afektif dan komitmen normatif terhadap kinerja karyawan dengan uji F maka diperoleh nilai F hitung > F tabel, 77,353 tingkat signifikansi 0,00 $<0,05$. berarti secara bersama-sama budaya perusahaan, komitmen afektif, komitmen normatif berpengaruh positif dan signifikan terhadap kinerja karyawan. Penelitian in dapat diperkuat dengan beberapa pendapat seperti menurut Steers (1983:35) yang menyatakan dampak dari budaya perusahaan, komitmen yang tinggi adalah menciptkan produktivitas karyawan yang tinggi Sehingga 
hipotesis terakhir berbunyi "terdapat pengaruh antara Budaya Perusahaan (X1), Komitmen Afektif (X2), Komitmen Normatif (X3) terhadap Kinerja Karyawan (Y)” diterima.

Hasil analisis statistik dalam penelitian ini membuktikan secara parsial bahwa variabel komitmen afektif dan komitmen normatif berpengaruh signifikan sedangkan variabel budaya perusahaan dalam penelitian ini tidak berpengaruh dan tidak signifikan terhadap kinerja karyawan PT Bank Bukopin Kantor Pusat. Variabel lain yang mempengaruhi kinerja karyawan PT Bank Bukopin Kantor Pusat sebesar 41,4\% kemungkinan dari penilaian terhadap kompensasi, gaji, tunjangan, bonus dan lain sebagainya yang tidak diteliti oleh penulis.

\section{KESIMPULAN}

Berdasarkan hasil penelitian berkenaan dengan budaya perusahaan, komitmen afektif, dan komitmen normatif berpengaruh terhadap kinerja karyawan PT Bank Bukopin, Tbk, maka diperoleh kesimpulan sebagai berikut :

1. Variabel budaya perusahaan tidak berpengaruh positif terhadap kinerja karyawan PT Bank Bukopin, Tbk kantor pusat 33,76 \%.

2. Variabel komitmen afektif berpengaruh signifikan terhadap kinerja karyawan PT Bank Bukopin, Tbk kantor pusat sebesar 21,46\%.

3. Variabel komitmen normatif terhadap kinerja karyawan PT Bank Bukopin, Tbk kantor pusat sebesar 17,06 \%., dan sisanya 41,4\% dipengaruhi oleh faktor variabel lain.

\section{SARAN}

Berdasarkan hasil penelitian dan keterbatasan penulis, maka saran yang dapat diberikan adalah sebagai berikut:

1. Proses internalisasi nilai-nilai budaya perusahaan harus dapat kembali disampaikan melalui saluransaluran lain seperti kunjungan langsung manajemen Board of Director (BOD), sosialisasi ditingkatkan melalui morning briefing pagi, satu sama lain terutama atasan dapat memberikan contoh, mengingatkan dan juga lakukaan pendidikan dan pelatihan coaching, counselling, teaching.

2. Komitmen Afektif dapat ditingkatkan lagi karen merupakan salah satu variabel yang dapat menunjang karyawan untuk meningkatkan kinerja dengan menciptakan suatu lingkungan yang kondusif dan nyaman untuk bekerja.

3. Komitmen Normatif harus terus dipelihara karena merupakan salah satu kelebihan PT Bank Bukopin, Tbk karena terdapat membangun semangat kekeluargaan, kebersamaan yang dapat meningkatkan kinerja PT Bank Bukopin, Tbk.

\section{DAFTAR PUSTAKA}

Algifari. 2012. Statistika Deskriptif untuk Ekonomi dan Bisnis. UPP STIM YKPN. Yogyakarta.

Alma, Buchari. 2011. Manajemen Pemasaran dan Pemasaran Jasa. Alfabeta. Bandung.

Anonimous. 2015. Kamus Besar Bahasa Indonesia. edisi keempat. Gramedia Pustaka Utama. Jakarta.

Hasan, Ali. 2011. Marketing. Media Utama. Yogyakarta.

http://search.proquest.com/docview/1448004718?acco untid $=38628$

http://belajarpsikologi.com/metode-pengumpulan-data/

Kotler, Philip. 2012. Marketing Management. Upper Sadle River.

Kotler, Philip dan Kevin Keller. 2012. Manajemen Pemasaran. Edisi Keempat Belas. Jilid 1. Erlangga. Jakarta.

Kotler, Philip dan Gary Armstrong. 2012. Dasar-dasar Pemasaran. Edisi Bahasa Indonesia. Jilid 1. Erlangga. Jakarta.

Sangadji, Etta M. dan Sopiah. 2014. Perilaku Konsumen. Edisi 1. CV. Andy Offset. Yogyakarta.

Sinaga Ferdinan. 2014. Pengaruh Biaya Bauran Promosi Terhadap Nilai Penjualan Produk Kursi Pijat Advance Di PT. SSB Jakarta.

Sugiyono. 2012. Metode Penelitian Kuantitatif Kualitatif dan R\&D. Alfabeta Bandung.

Sugiyono. 2014. Metode Penelitian Manajemen. Alfabeta Bandung

Sunyoto, Danang. 2014. Dasar-Dasar Manajemen Pemasaran (Konsep Strategi dan Kasus). CAPS (Center of Academic Publishing Service). Yogyakarta.

Sunyoto, Danang. 2013 Teori, Kuisioner \& Analisis Data Untuk Pemasaran dan Perilaku Konsumen. Cetakan Pertama. Yogyakarta.

Hariandja, M.T.E., 2002. Manajemen Sumber Daya Manusia. Jakarta : Penerbit PT. Gramedia Widiasarana Indonesia.

Hasibuan, M.S.P., 2003. Manajemen Sumber Daya Manusia. Jakarta : PT. Bumi Aksara.

Heidjrachman Dan Husnan S., 2008. Manajemen Personalia. Edisi 4. Cetakan Kesebelas. Yogyakarta : BPFE.

Kreitner R. And Kinicki A., 2003. Perilaku Organisasi. Penerjemah : Erly Suandy. Jakarta : Penerbit Salemba Empat.

Luthans F., 2006. Perilaku Organisasi. Edisi Sepuluh, Penerjemah : Vivin Andhika Yuwono, dkk., Yogyakarta : ANDI. 
Mangkunegara, Anwar Prabu, 2002 Manajemen Sumber Daya Manusia Perusaahaan. Bandung : PT. Remaja Rosdakarya. , 2009. Evaluasi Kinerja SDM. Bandung: PT. Refika Aditama.

Nawawi, Hadari, 2005. Manajemen Sumber Daya Manusia. Untuk Bisnis Yang Kompetitif. Cetakan Keenam. Yogyakarta : Gadjah Mada University Press.

Ndraha, T., 1999. Pengantar Teori. Pengembangan Sumber Daya Manusia. Jakarta : PT. Rineka Cipta.

, 2005. Teori Budaya Organisasi. Jakarta : PT. Rineka Cipta.

Rivai, Veithzal. 2008. Manajemen Sumber Daya Manusia untuk Perusahaan dari Teori Ke Praktik. Jakarta : PT RajaGrafindo Persada. , 2008. Kepemimpinan dan Perilaku Organisasi. Edisi Kedua. Jakarta : PT. RajaGrafindo Persada.

Robbins, S.P., 2006. Perilaku Organisasi. Alih Bahasa : Benyamin Molan. Jakarta : PT. Indeks Kelompok Gramedia.

Robbins, S.P. and Judge, T.A. 2008. Perilaku Organisasi. Organizational Behavior. Buku 1. Edisi 12. Penerjemah : Diana Angelica. Jakarta : Penerbit Salemba Empat.

Silalahi, Benneth, 2004. Corporate Culture \& Performance Appraisal. Budaya Perusahaan dan Penilaian Unjuk Kerja. Cetakan Kesatu. Jakarta : Yayasan Pendidikan Al Hambra.

Siswanto H.B., 2008. Pengantar Manajemen. Cetakan Keempat. Jakarta : PT. Bumi Aksara. Supriyanto, E.B., 2006. Budaya Kerja Perbankan, Jalan Lurus Menuju Integritas. Jakarta : Pustaka LP3ES Indonesia.

Tampubolon, Manahan P. 2008. Perilaku Keorganisasian dalam Perspektif Organisasi Bisnis. Bogor : Ghalia Indonesia.

Terry, George R., 2006. Asas-Asas Manajemen, Edisi Kedelapan, Cetakan Kelima, Alih Bahasa : Winardi. Bandung : PT. Alumni.

Tika, Pabundu, Moh. 2006. Budaya Organisasi dan Peningkatan Kinerja Perusahaan. Jakarta : Bumi Aksara.

Wibowo, 2007. Manajemen Kinerja. Jakarta : PT. Raja Grafindo Persada.

Winardi J., 2002. Motivasi dan Pemotivasian dalam Manajemen, Edisi Pertama, Cetakan Kedua. Jakarta : PT RajaGrafindo Persada.

Wirawan. 2007. Budaya dan Iklim Organisasi (Teori Aplikasi dan Penelitian). Jakarta : Penerbit Salemba Empat. 